\title{
4 \\ WHAT IS NATIONAL BIOGRAPHY FOR? DICTIONARIES AND DIGITAL HISTORY
}

\author{
PHILIP CARTER
}

Ask the purpose of national biography and you may be forgiven for thinking this an easier question for previous generations to answer. In June 1900 the original British Dictionary of National Biography (DNB) reached its completion with the publication of a 63 rd and final volumean event hailed as a triumph by reviewers and compilers alike. For the Pall Mall Gazette, this was 'the best dictionary of home biography possessed of any nation', while the Athenaeum championed 'our British lexicographers' who 'have had the satisfaction of administering a handsome beating to their most formidable rivals, the Germans'. ${ }^{1}$

The $D N B$ 's editor at the time was the Elizabethan literary scholar Sidney Lee, who had driven the project on during the 1890s and infused it with an enhanced degree of scholarly rigour. Lee celebrated the Dictionary's completion in similarly confident fashion, praising an 'undertaking of exceptional magnitude in the history of publishing' that was more extensive, coherent, and rapidly produced than 'cyclopaedias of national

1 Quoted in Keith Thomas, Changing Conceptions of National Biography: The Oxford DNB in Historical Perspective (Cambridge: Cambridge University Press, 2005), 27. doi.org/10.1017/CBO 9780511497582; 'Dictionary of National Biography. Edited by Sidney Lee-Vol. LXII', Athenaeum, 14 July 1900, 45, quoted in Juliette Atkinson, Victorian Biography Reconsidered: A Study of Nineteenth-Century 'Hidden' Lives (Oxford: Oxford University Press, 2010), 231. doi.org/10.1093/ acprof:oso/9780199572137.001.0001. 
biography abroad', including those of Belgium, the Netherlands, Sweden, the United States of America, and again Germany. For Lee, the Dictionary also served as a record of incremental national progress over time, and especially the century just passed: a charting of 'the multiplication of intellectual callings' by which 'the opportunities of distinction have been of late conspicuously augmented'. ${ }^{2}$ Lee's view echoed earlier assessments, including one from Henry Reeve, editor of the Edinburgh Review, for whom the Dictionary's opening volumes offered 'striking proof of the advancement of civilization' that was 'honourably characteristic of the present age. ${ }^{3}$ Ask 'what national biography was for' in 1900 and the answer seems clear: to facilitate national and historical comparisons that revealed the British to be best, and the late Victorian British to be best of all.

Nor was this idea of national biography as national celebration and self-definition reserved for the British. Those rival dictionaries, which Lee and others considered too partial or too slow to appear, were themselves formations and expressions of new nation states. As Iain McCalman has argued:

whereas a newly established state of the late twentieth century might seek to patent its identity by funding a national airline service; its nineteenth-century counterpart was likely to have launched a multi-volume biographical dictionary so as to display historical credentials, to define geographical, linguistic and cultural boundaries, and to instil a unified sense of national pride. ${ }^{4}$

McCalman's observation appears in his 'Introduction' to the proceedings of the conference, held in Canberra in February 1995, at which national biographers first gathered to discuss the relationship of 'National Biographies and National Identity', and on which contributors to this latest volume reflect and build following a second gathering two decades later.

2 Sidney Lee, 'A Statistical Account', Dictionary of National Biography, vol. 63, WordsworthZuylestein (London: Smith, Elder and Co., 1900), i, vii-xi.

3 Henry Reeve, 'The Literature and Language of the Age', Edinburgh Review, 169 (August 1889), 350, quoted in Atkinson, Victorian Biography Reconsidered, 232.

4 Iain McCalman, 'Introduction', in National Biographies and National Identity: A Critical Approach to Theory and Editorial Practice, eds Iain McCalman with Jodi Parvey and Misty Cook (Canberra: Humanities Research Centre, The Australian National University, 1996), i; also Peter Burke, A Social History of Knowledge, vol. 2, From the Encyclopédie to Wikipedia (Cambridge: Polity Press, 2012), 192-97. 
By the time of the first Canberra conference, work was underway on a completely new, and considerably extended, edition of the British Dictionary of National Biography, subsequently published simultaneously in print and online as the Oxford Dictionary of National Biography $(O D N B)$ in 2004. Its founding editor, the nineteenth-century historian Colin Matthew, was present in Canberra in 1995 and used a lecture on that occasion to consider the purpose of his new Dictionary. For Matthew, a late twentieth-and early twenty-first-century national biography would be a work of historical record: a gathering and assessment of contributions by a historical profession whose origins owed much to the structures and practices developed during the making of the original $D N B$. In addition, Matthew envisaged the new Dictionary as serving current members of the historical and humanities professions in teaching and research: 'The modern national biography will be the first point of reference for anyone interested in the British biographical past'. 5 It would, as he presciently noted, also exist as a predominantly digital (or as it was described then an 'electronic' or 'computerised') resource. Matthew's national biography would therefore combine classic reference (being the first place to which people in search of information would go), with the potential for connections and lines of enquiry hitherto untraced. Online reference would, in turn, be the gateway to transnational integration prompted by ineluctable political and technological transition. 'As nationality in Europe gives way to the European Union', he suggested, 'so national reference works, at least in Europe, will do so also' while, thanks to their online existence, 'we will see the gradual aggregation of our various dictionaries of national biography'. ${ }^{6}$

Though issued nearly a century apart, these two statements of national biographical purpose-Lee's from 1900, Matthew's from 1995-are defined in their different ways by confidence in a job well done and optimism for the future. But where are we now-and 'what is national biography for'-nearly 25 years on from Colin Matthew's observations? Certainly the present and the future course of national biography may

5 H. C. G. Matthew, Leslie Stephen and the New Dictionary of National Biography (Cambridge: Cambridge University Press, 1997), 37.

6 H. C. G. Matthew, 'Dictionaries of National Biography', in McCalman with Parvey and Cook, National Biographies and National Identity, 16-17. Integration of national biographies was also anticipated by Robert Faber and Brian Harrison (respectively the ODNB's project director and general editor) in 'The Dictionary of National Biography: A Publishing History', in Lives in Print: Biography and the Book Trade from the Middle Ages to the 21st Century, eds Robin Myers, Michael Harris, and Giles Mandelbrote (New Castle, DE: Oak Knoll Press, 2003), 189. 
initially seem rather less certain. For what defines this short time span is a transformation-possible to anticipate in 1995 but impossible to predict in its extent-in information gathering, storage, retrieval, and dissemination. It is a transformation well captured in a recent history of reference publishing by the American literary scholar Jack Lynch, who describes the two decades that separate the Canberra conferences of 1995 and 2016 as the most turbulent in the long history of a traditionally stable form of scholarship and publishing. Central to this change is, of course, the rise of user-driven content and online resources such as Wikipedia, vast both in terms of scope and the speed of its revision. As Lynch argues, more has changed in the last 20 years with regards to reference publishing than in the previous 3,000. The result is an 'information monoculture', dominated by Wikipedia, which-despite its being a non-commercial venture-poses to information provision many of the dangers of a traditional monopoly. ${ }^{7}$

It is not hard to see why such developments may be unwelcome for national biography, not least since life writing, especially of figures in western historical and contemporary culture, has been a major area of recent growth for sites like Wikipedia. There are, moreover, further potential challenges to the genre of national biography at this time. Prominent among these is the historiographical trend for transnational and global studies that question the value of the nation state (and so perhaps the national dictionary, however broadly defined) as a meaningful category for human activity in the past. Significant too are digital histories, grounded in analysis of 'big data', that encourage longer-term periodisation and studies of human activity in aggregate, and which similarly often, and determinedly, transcend the political and cultural identities that first gave rise to national biographies. ${ }^{8}$ And closer to home there is the ongoing debate within Britain about the stability of the United Kingdom itselfstirred by devolution in the late 1990s, the subsequent rise of political nationalisms, and now reignited following the June 2016 vote to leave the European Union-which prompts further questions about the future

7 Jack Lynch, You Could Look It Up: The Reference Shelf from Ancient Babylon to Wikipedia (London: Bloomsbury Press, 2016), 389.

8 See Jo Guldi and David Armitage, The History Manifesto (Cambridge: Cambridge University Press, 2014), ch. 4; and David Armitage and Jo Guldi, 'The Return of the Longue Durée: An AngloAmerican Perspective', Annales. Histoire, Sciences Sociales, 70, no. 2 (2015): 219-47. doi.org/10.1017/ S2398568200001126 in which biography — with its focus on 'a purportedly diachronic category of "character"- -is contrasted with the 'power of digital tools to promote longue durée synthesis that includes perspectives other than that of the nation-state' $(227,245)$. 
of the British nation state. Viewed from the mid to late 2010s, therefore, the Athenaeum's late Victorian equation of national biography as personification and celebration of a definable nation, or Matthew's claim to provide an increasingly transnational 'first point of reference' for a new digital age, seem less secure than they once did. The journey of national biography - now undertaken across a landscape of digitised research practices and publishing - could, in short, be one nearing its terminus.

Notwithstanding these challenges, and while not denying their significance and as yet unresolved consequences, this chapter seeks to offer a more optimistic response regarding the purposes of contemporary national biography within a research context that has seen considerable recent change. The scholars and their projects who gathered in July 2016 for the second Canberra conference are evidence that national and collective biographies remain many and varied, active and ambitious. Moreover, as the work of an earlier generation of biographers has come to fruition-through first-time publication (of, say, the Oxford DNB) or continuation (of the Australian Dictionary of Biography)—national biography has re-emerged to become an accepted staple of contemporary humanities research and scholarly literature. That individual entries within national biographies are read, and regularly cited, suggests this is a genre with credibility and reinvigorated scholarly purpose. Even so, an important question remains: how far does this sense of purpose extend beyond the individual biography, and the notion of online dictionaries as 'super accessible print', ' to become something more dynamic, integral, and valuable to contemporary scholarship? That is, to become both a beneficiary of, and a contributor to, new forms of historical practice that serve to realise and disseminate ambitions championed by earlier, predigital editors like Lee and Matthew.

Key to this chapter is the assertion that national biography is on the cusp of significant development and opportunity, and that-broadly speaking — we should be enthusiastic about this, and about how national biography may be incorporated within and contribute to emerging forms of historical scholarship. At the heart of this more positive future for national biographies are, of course, the same digital transformations that have reshaped reference publishing in recent years, and have shaken some

9 Philip Carter, 'Opportunities for National Biography Online: The Oxford Dictionary of National Biography, 2005-2012', in The ADB's Story, eds Melanie Nolan and Christine Fernon (Canberra: ANU E Press, 2013), 346. doi.org/10.22459/ADBS.10.2013.11. 
of the core beliefs that characterised the first Canberra gathering in 1995 . To embrace digital opportunities in the mid to late 2010 s does not require national biographers to compete directly with online alternatives, but rather to identify and promote ways in which their work is both distinctive (and in some ways superior) but also integral to the digital ecosystem that we inhabit when undertaking historical study. Central to this concept of national biography is the potential it now provides to undertake original academic research: the ability to use national biographies both as written collections and as data to make connections and trace patterns that could not be identified without the existence of collective biography in digital form.

\section{'True national biography': Who Could and Who Should Be Included?}

If future prospects offer promise, it is equally the case that the historical aims and ends of national biography have been rather more contested. Thus, despite the positive opinions quoted at the start of this chapter, it would be wrong to assume that former dictionary-makers necessarily shared a common purpose in their endeavours. In truth, debate and differences of opinion have characterised the making of the Dictionary of National Biography from its origins in the 1880s, and on occasions to a degree that would raise concern in a modern publishing house or academic department. The confident patriotism championed in June 1900 was, in large part, the verdict of the press, rather than of those directly involved in the $D N B$ 's conceptualisation and composition. Principal among these less emphatic dictionary-makers was the $D N B$ 's founding editor, Leslie Stephen, who served in this capacity from 1882 until 1891 when, suffering from ill health, he gave way to his deputy, Lee.

Stephen's conception of national biography was defined less by singularity and superiority than diversity and movement. For Stephen, a collective statement on national identity was required to embrace the international connections that shape any nation, and which had been an especially important theme in British history. As Matthew argued, the 'national' in Stephen's 'national biography' was 'inclusive, fluid and pragmatic, and in a sense international'. ${ }^{10}$ In the light of this, it comes as little surprise that

10 Matthew, Leslie Stephen, 36. 
in Stephen's $D N B$ - a work celebrated in some quarters for its beating of continental rivals - the first entry was for Jacques Abbadie (baptised 1654?-1727), a future dean in the Church of Ireland, who hailed from Béarn, France; and the last William van Nassau van Zuylestein, who was born near Utrecht in the early 1690s.

The contested nature of Victorian national biography can also be seen in a series of striking intereditorial debates over who should, and should not, be prioritised for inclusion. In January 1896 Lee, then nearly five years into his editorship, lectured on 'National Biography' at the Royal Institution, London. Lee engaged directly with the question of inclusion and especially his understanding of national biography as a record of 'people of distinction'. Biography, he argued, was the literary format best placed to commemorate those who 'by character and exploits, have distinguished themselves from the mass of their countrymen', and whose achievements are-as he later wrote- 'capable of moving the interest of posterity' and outliving the 'fashion or taste of the hour'. ${ }^{11}$ Several months on, Stephen gave his response in a lecture, also entitled 'National Biography', and subsequently published in the National Review. In contrast to Lee's focus on commemorating and memorialising the distinguished, Stephen championed what he termed the 'second-rate people ... whose lives have to be reconstructed from obituary notices or from references in memoirs and collections of letters'. ${ }^{12}$ In doing so, he echoed views from an earlier essay that it was the 'timid and third-rate lives' who would 'prove the real test of the value of the book ... the less conspicuous people about whom it is hard to get information elsewhere'. ${ }^{13}$ They, for Stephen, were the core purpose of national biography. To modern readers, of course, it is less Stephen than his daughter, Virginia Woolf, who is most closely associated with this notion of the 'hidden' or 'little' life as equally worthy of historical record. Woolf's celebrated challenge-'Is not anyone who has lived a life, and left a record of that life, worthy of biography ... the humble as well as the illustrious?'- - served for later generations as a Bloomsbury swipe at late Victorian biography and the makers of voluminous national

11 Sidney Lee, 'National Biography', Cornhill Magazine, 26 (March 1896), 258; Sidney Lee, Principles of Biography (Cambridge: Cambridge University Press, 1911), quoted in Atkinson, Victorian Biography, 224.

12 Leslie Stephen, 'National Biography', National Review 27 (1896), reprinted in his Studies of a Biographer, 4 vols (London: Duckworth and Co., 1898), 1:21-22.

13 Leslie Stephen, 'Biography', National Review, 22 (1893-94): 176-77, quoted in Atkinson, Victorian Biography, 222. 
biographies. ${ }^{14}$ But in many ways Woolf's father got there first, and was himself building on the interests of an earlier generation of biographers, as Juliette Atkinson has shown. ${ }^{15}$ For Stephen, national biography was a unique publishing opportunity—not just to record Lee's 'emulative' or Woolf's 'illustrious', but also to reconstruct those forgotten individuals whose lives have 'to be painfully dug out of collections of manuscripts', or pieced together from 'references in memoirs and collections of letters'. ${ }^{16}$

If such debates show the purpose of 'national biography' to have been long contested, they also remind us that the journey taken by the $D N B$ from the late nineteenth to the early twenty-first century-is one of continuation and evolution rather than sudden transition or redefinition. The continuities that shape national biography are clearly apparent when today's editors consider the question of inclusion: who should we add, and why? Here the current purpose of the Dictionary resonates with both that of Stephen and Lee, notwithstanding their public disagreements on this subject. Contemporary Oxford editors define their national biography as a record of historically 'noteworthy' lives; that is, people of interest to scholars who will, it is expected, continue to be of significance for later generations-not just with regard to the person him or herself, but also as commentaries on what historians of the time thought worthy of record. To do so follows Lee's call to remember those 'capable of moving the interest of posterity', albeit without Lee's insinuation of the moral value of such distinguished lives. At the same time, they heed Stephen's injunction to reconstruct biographies of forgotten individuals whose life stories are 'dug out' from manuscripts or pieced together from references in memoirs and correspondence.

The opportunities to dig, discover, and reconstruct are today considerably enhanced by the growing availability of digitised resources. This provision and accessibility of biographical data is a further transformation that distinguishes the research environment of the mid-1990s from that of the present day. In the United Kingdom alone these digitally accessible resources include (to name just the principal primary records): census returns from 1841 to 1911; registers of births, marriages, and deaths

14 Virginia Woolf, 'The Art of Biography' (1939), in Selected Essays, ed. David Bradshaw (Oxford: Oxford University Press, 2009), 121.

15 Atkinson, Victorian Biography. On the proximity of Stephen and Woolf, see also Alison Booth, 'Fighting for Lives in the ODNB: or Taking Prosopography Personally', Journal of Victorian Culture 10 (2005): 270-71. doi.org/10.3366/jvc.2005.10.2.267.

16 Stephen, Studies of a Biographer, 1:22. 
for England and Wales from 1837, and Scotland from 1854; and parish registers providing details of births, baptisms, marriages, deaths, and burials for earlier periods. Many biographers and historians now also have access to digitised electoral registers, poll books, telephone directories, passenger embarkation and disembarkation lists, criminal registers and prison records, transportation lists, trade directories, medical and nursing registers, military service and medal files, scanned copies of early modern wills held at the National Archives, and probate records from the 1860s onwards. To this can be added millions of pages of national and regional newspapers from the seventeenth to the nineteenth centuries, and selected national newspapers into the early twenty-first century. Leading this expansion of sources is Ancestry.com, which, as of 2015, had made available some 14 billion documents worldwide. In the United Kingdom, meanwhile, D. C. Thompson, creators of Find My Past, have been responsible for the digitisation of a further 1.8 billion records. ${ }^{17}$

In the wake of these records have come new opportunities for the construction of biographies, digitally and step by step, 'from the bottom up'. As a result, the possibilities for inclusion in a national biography have expanded markedly, even since the Oxford DNB's first publication in 2004. Such first-time 'discoveries' are now numerous, among them one Henry Croft (1861-1930), founder in the late 1890s of the London tradition of pearly kings and queens who, arranged in city-wide networks modelled on the royal family, undertook charitable activities. ${ }^{18}$ Such a figure is an obvious candidate for the Oxford $D N B$ given his contribution to late Victorian voluntarism, and a legacy of charitable dynasties that continue to thrive across the London boroughs. Googling 'Henry Croft' a few years ago revealed no shortage of references to the man and his 'pearly kings'; but it was equally clear that much of this material was partial, anecdotal, and repetitious. This is online history at its least edifying, though it is more than made up for by the digitised sources that enabled his life story to be reconstructed.

17 David Thomas and Valerie Johnson, 'From the Library in Alexandria to the Google Campus: Has the Digital Changed the Way We Do Research?', in Is Digital Different?, eds Michael Moss, Barbara Endicott-Popovsky, and Marc J. Dupuis (London: Facet Publishing, 2015), 192.

18 Philip Carter, 'Croft, Henry [called the Original Pearly King] (1861-1930)', Oxford Dictionary of National Biography, Oxford University Press, May 2012; online edn, October 2012, accessed 17 April 2017. doi.org/10.1093/ref:odnb/97112. 
The starting point for Croft's life story came at its end with the chance discovery of a Pathé News clip of his funeral procession, broadcast in January 1930. With an approximate death date, it was possible to search the digitised indexes of the General Register Office with a degree of precision. Croft's death certificate provided his place of death (the St Pancras workhouse, close to the modern British Library); his age at death (68 years); and his profession-for his entire working life, from 1876 to 1928, Henry worked as a road sweeper for the St Pancras Corporation. Knowing his age at death made possible a search for his birth certificate, which revealed he had been born-also at the St Pancras workhouse-on 24 May 1861. These markers enabled a trawl of the census returns for 1861 onwards to fill out details of Henry's wider family: his parentsJohn, a street musician who died in 1871, and his mother, Elizabeth. Henry's death certificate also provided the forename of his wife, Lily, who witnessed this record in 1930. This led to Lily Newton (1874-1940), the daughter of a Kentish Town house painter, whom Henry married at Bedford New Town Chapel, St Pancras, in February 1892. From here, again using the census returns, it was possible to piece together Henry and Lily's married life: their family (by 1911 nine children aged between 17 years and eight months) and their residences: from 1901 the Crofts lived at 15 Charles Street, off the Euston Road, in a 10-room house they shared with another family, the Wilsons and their three children. A digital edition of Charles Booth's poverty maps and police notebooks for 1898 provides further information about Croft's domestic environment ('good working-class'), ${ }^{19}$ while digitised newspapers and periodicals led to his first known appearance as a public figure: a 1902 magazine article introducing 'Mr Croft', the 'Pearlie king of Somers Town', photographed in a handmade suit of 5,000 buttons. Subsequent newspaper articles identified Croft in various 'pearly' roles: raising money for charity, taking part in annual horse and donkey shows, and a meeting with Edward VII at Olympia in $1907 . .^{20}$

19 'Charles Booth's London', London School of Economics \& Political Science, accessed 17 April 2017, booth.lse.ac.uk; London School of Economics, University of London, Booth MSS, B/356.

20 On the contribution of digital resources to late nineteenth- and early twentieth-century working-class biography, see also Tim Hitchcock and Robert Shoemaker, 'Making History Online', Transactions of the Royal Historical Society 25 (2015): 75-93. doi.org/10.1017/S0080440115000031. As Hitchcock and Shoemaker demonstrate: 'In half an hour's search we can put together a life, an experience and an emotional and empathetic contact with one of the more than three million mostly anonymous men and women who lived in London in 1871' (78). 
In writing a life of Henry Croft (and many like him), the availability of digitised sources is clearly of enormous benefit. Returning to the question 'what is national biography for?', Croft's example shows the modern genre to be more than a conspectus of existing information distilled into a reference format; rather it is now in addition a home for, and generator of, first-time research. However, ready access to first-time information about ever-greater numbers of historical individuals also raises an important question: where should editors stop when it comes to adding people to a national biography? It is one first considered in 2004 by the historian Keith Thomas in a lecture to mark publication of the Oxford DNB. As Thomas noted, following the rise of social and cultural history, scholars were now engaging with all sections of past populations, and often doing so-in the wake of the 'biographical turn'-via the medium of individual and group lives. 'There is in principle', he continued, 'no reason why many of these hidden lives should not be recovered, and there is no technological obstacle to storing them electronically. One day perhaps we may have a database so vast that its claim to be a true national biography will be incontrovertible. ${ }^{21}$

Thomas's proposal is a common reference point for each of the chapters in this volume. However, it seems of special significance when considering the potential influence of digital research practices and digital publishing. In short, is a 'true national biography', comprised of the myriad lives now traceable online, a suitable destination for current journeys in, and conceptions of, national biography? This is particularly interesting in the context of the Oxford DNB, which has adopted 'historical noteworthiness' as its defining criterion for inclusion-a framing principle distinct from the notion of 'representativeness' that shapes the population of, for example, the Australian Dictionary of Biography $(A D B)$. 'Noteworthiness' is a historical judgment on who is now, and seems likely to be, considered of interest to current and future generations of scholars, as determined by the historians and editors whose judgments concerning article length also speak to an understanding of a person's relative historical significance. While equally alert to subjects' relative importance, 'representativeness' places greater emphasis on reflecting the past through a spectrum of lives that best characterise a particular period. ${ }^{22}$

21 Thomas, Changing Conceptions of National Biography, 56.

22 On representation as a framing principle of the $A D B$, see Paul Longley Arthur, 'Biographical Dictionaries in the Digital Era', in Advancing Digital Humanities: Research, Methods, Theories, eds Katherine Bode and Paul Longley Arthur (London: Palgrave, 2014), 83-94. doi.org/10.1057/ 9781137337016_6; and 'Re-imagining a Nation: The Australian Dictionary of Biography Online', European Journal of Life Writing 4 (2015): 108-24. doi.org/10.5463/ejlw.4.163. 
Noteworthiness creates boundaries on who should be included, as judged by historically informed editors, and so sets limits on Thomas's idea of an ever larger database that points to a 'true national biography', defined more by scale than historical evaluation. Editors at the Oxford DNB regularly receive correspondence from relatives seeking the inclusion of a forebear. Some are excellent suggestions and are reviewed and added to the Dictionary. But others are not considered 'noteworthy' and for these are suggested alternative forms of publication-including blogs, Wikipedia, or social media - that have greatly expanded the opportunities for life writing in the decade and a half since Thomas's observation. In this context, one purpose of contemporary national biography may be to hold the line between who should be included and who could be included, based on historical assessment-irrespective of whether (or indeed precisely because) that life can now be written with access to digital sources.

\section{National Biography and Digital History}

The remainder of this chapter maintains a focus on contemporary national biography but shifts from individual lives to consider a little further its purpose as a genre, especially in the context of digital historical practices and the discipline of digital history. Three areas-extensibility and audience, engagement with user-generated content, and potential research options - will be highlighted with examples of work recently undertaken by editors at the Oxford DNB. With inevitable challenges come new opportunities, if - as academics and publishers-we adopt a broader conception of the scholarly purposes of historical reference. These proposals are, therefore, three reasons for cautious optimism as regards future journeys for national biography.

As digital collections national biographies are, firstly, highly adaptable and extensible, not least through external and reciprocal linking. When it was first published in 2004, the Oxford DNB already had in place many thousands of links to external resources that connected individual biographies to, for example, images of the subject in the National Portrait Gallery or to his or her papers listed in the National Archives. In a program begun in 2015, Oxford editors have since extended the number and scope of these curated connections. Recently added links now provide onward journeys to writers' digitised manuscripts in the British Library; to records of subjects' funeral monuments in Westminster Abbey; 
to images and addresses of houses in which a person lived (via English Heritage's Blue Plaque scheme); and to historical voice recordings held by the British Library, the Poetry Society, and the British Broadcasting Corporation's (BBC) radio and film archive. Further project partnerships have established reciprocal links to the financial records of British slaveowners (drawing on records at the National Archives, and now recorded via the 'Legacies of British Slave-Ownership' website); to Art UK, which connects 2,200 British artists in the Oxford DNB to digitised galleries of their art works held in public collections; and to the Commonwealth War Graves Commission website, which provides additional information on service, death, and burial for the Dictionary's military personnel killed in combat since $1914 .{ }^{23}$

These linking projects offer interesting alternative perspectives on a person's life. With them, Dictionary users are now able to move from a traditional biographical text to examples of manuscript works revealing an author's hand and working methods; the house and street where a person lived, and who else in the $O D N B$ lived nearby; or the sound of their voice or sight of their mannerisms via sound and film footage. This ability to see a person or to hear them speak is a particularly important innovation. Like nothing else, it reminds us that a distant historical figure was a living person as well as the subject of a biographical text. Sound and vision promise to bring a new dimension to national biography, and could be extended, for example, to performance recordings for historical musicians, or archive commentaries for sporting figures. It is also worth noting that while these additions are relatively new, they have long been considered. At the first Canberra conference in 1995, the Oxford DNB's founding editor, Colin Matthew, foresaw the potential of digital national biography, predicting that 'we may in time be able to have Churchill's memoir ... plus a recording of him speaking, and a film of him electioneering'. ${ }^{24}$ In 2016 a recording of the prime minister's 'Finest Hour' speech was at last made available via links from the $O D N B$ 's Churchill biography to the $\mathrm{BBC}$ 's sound and film archive.

23 'Legacies of British Slave-ownership', University College London, accessed 17 November 2018, www.ucl.ac.uk/lbs/; 'Art UK', artuk.org/; 'Commonwealth War Graves Commission', accessed 17 November 2018, www.cwgc.org.

24 Matthew, 'Dictionaries of National Biography', 16. See Paul Addison, 'Churchill, Sir Winston Leonard Spencer (1874-1965)', Oxford Dictionary of National Biography, Oxford University Press, 2004; online edn, September 2004. doi.org/10.1093/ref:odnb/32413. 
Online national biography is also extensible in terms of its format, of which the Oxford DNB's biography podcast-comprising more than 300 recordings-is one notable instance. With some editing, the consistent format of a national biography entry lends itself well to a scripted podcast. Episodes range from 10 minutes to narrate the life of John Simpson Kirkpatrick (1892-1915), the 'Man with the Donkey' at Gallipoli, to 40 minutes for an edited version of the life and legacy of the author and advocate of women's rights, Mary Wollstonecraft (1759-1796). Originally available free via the $O D N B$ site and iTunes, recordings are now also accessible on the music and streaming platform SoundCloud. ${ }^{25}$ With roughly 50,000 downloads per month, this variation on the biographical form is both popular and readily discoverable, making scholarly content available to many, worldwide, who would not otherwise engage with a work of historical reference. Other forms of social media, notably Twitter, have also been embraced by $O D N B$ editors as channels not just for promoting content but also to observe third-party conversationstypically among digitally literate postgraduate researchers-about the project, its strengths, and its weaknesses. Social media comments identifying historical individuals not yet in the Dictionary have led to the commissioning of a number of new biographies, including for the linguist Claudius Hollyband (1534/5-1597) and the designer Peggy Angus (1904-1993).

Coming of age in the era of Web 2.0, modern national biographies and their editors must balance positives of this kind with potentially less welcome developments, of which user-generated reference content-and Wikipedia especially_is a prime instance. Here, as Lynch identifies, is a resource and a resulting research culture that risks threatening the meaningfulness and utility of scholarly reference and national biography as we understand it: as curated collections of content written by, and attributed to, specialist authors in processes of creation and revision, overseen by academic editors. Wikipedia-and specifically whether, and how, these academic editors engage with this resource-provides a second intersection of national biography and digital history. For its part, the Oxford $D N B$ has pursued a course of pragmatic accommodation, appreciative of the fact that such resources cannot be 'beaten' on account of their scale, accessibility, and popularity. Editors have therefore worked profitably with the Wikipedia community to add and standardise

25 'Oxford DNB', SoundCloud, accessed 17 November 2018, soundcloud.com/odnb. 
citations to the $O D N B$ or to create links from a Wikipedia entry to a relevant biography on the Oxford site. Via these links it is possible for the $O D N B$ to remain if not Matthew's 'first' then at least the second 'point of biographical reference' for many students - and perhaps still to retain its status within British historiography as the principal work of curated scholarly reference. Whether this engagement will go further, extending even to the uploading of national biographical content on Wikipedia, as proposed by Kent Fitch, is open for debate and will likely be determined by the funding structures adopted by individual dictionaries. ${ }^{26}$

While collaboration has proved productive, equally we should not overlook those qualities that continue to distinguish national biography in an age of user-generated reference. In 2006 the radical historian Roy Rosenzweig, himself a pioneer in digital history, undertook a comparative survey of biographical content in Wikipedia and the online edition of the American National Biography $(A N B)$. Rosenzweig concluded that on the matters of factual accuracy there was little to distinguish the entries in these two sources. However, as works of history-that is, as written texts, composed and edited by subject specialists- $A N B$ content was both of markedly higher quality and of a form and length that more accurately reflected scholarly evaluations of historical significance. ${ }^{27}$ Since the editorship of Leslie Stephen, national biographies have been compiled and evaluated as historical works, not just as encyclopedias-a process that requires close attention to and an expectation of the artistry, clarity, and judgment of good historical writing. This will come as no surprise to those responsible for compiling and editing national biographies, but it is worth remembering when promoting such works to students.

As a determinedly neutral synthesis of 'what is known', Wikipedia also resists original research or informed opinion. Modern national biographies are, by contrast, increasingly rich repositories of first-time scholarship thanks to their growing appreciation of digitised resources and research practices. As noted, this potential for new biographical writing is at the same time corralled by the editorial principles-be it noteworthiness,

26 Kent Fitch, 'ADB v. Wikipedia', Biography Footnotes, no. 16 (2016): 13-17. Similar uses for Wikipedia are proposed by academic advocates of open-access publishing. See Paul Martin Eve, Open Access and the Humanities (Cambridge: Cambridge University Press, 2014), ch. 4. doi.org/10.1017/ CBO9781316161012.

27 Roy Rosenzweig, 'Can History Be Open Source? Wikipedia and the Future of the Past', Journal of American History 93, no. 1 (2006): 117-46. doi.org/10.2307/4486062, reprinted in his Clio Wired: The Future of the Past in the Digital Age (New York: Columbia University Press, 2010). 
representativeness, or some other-that underpin and frame an individual national biography. In each case editorial curation, however defined, brings with it a degree of informed selection. This, for many, is another increasingly important attribute of modern national biography given our ability to generate and suffer from 'information overload'. As Paul Arthur has recently argued - in a comment relevant to national biographers in the round-while the purpose of the Australian Dictionary of Biography remains 'to remedy the paucity of knowledge of Australians in history', it is increasingly the $A D B$ 's capacity to 'counteract the overabundance of information [that] is now proving most valuable for many'. ${ }^{28}$

Overabundance is not, it is worth remembering, a perception reserved for the digital era. In his 1896 lecture, Stephen spoke with ambivalence of the 'innumerable sources of knowledge' that had recently become available and which now threatened to overwhelm the late Victorian historian. As Stephen candidly admitted, to visit the British Museum reading room and look at the gigantic catalogue of printed books, and remember the huge mass of printed materials' brought forth 'a kind of nightmare sensation' ${ }^{29}$ In seeking 'a means of cutting through the morass of information', it was to national biography that Stephen turned as one of the 'contrivances for making it accessible'. This notion of the $D N B$ as an 'indispensable guide' to useful knowledge was, he concluded, 'the end that the national dictionary is intended in the first place to correspond ... Every student ought, I will not say to have it in his personal library, but at least to carry it about with him (metaphorically speaking) in his pocket'. ${ }^{30}$ Defined in this way, 'true national biography' in the twenty-first century, as in the late nineteenth, might be understood less in terms of extent than, in the context of multiplying sources of ill-defined provenance, as a historically informed and curated collection of lives that best facilitates study of the national past. Stephen's promotion of the multivolume $D N B$ as a new device for consolidating and containing information is also striking, not least given the consequences of later technological advances

28 Arthur, 'Biographical Dictionaries in the Digital Era', 89.

29 Stephen, 'National Biography', 9.

30 Stephen, 'National Biography', 11. Earlier intersections of information abundance and reference publishing are considered in Ann M. Blair, Too Much to Know: Managing Scholarly Information before the Modern Age (New Haven: Yale University Press, 2010), ch. 5. Stephen also considered excess in his 1893 essay on 'Biography' in which the national dictionary served as a 'literary condensing machine' and the national biographer as bringing 'into some sort of order ... the chaos of materials which is already so vast and so rapidly accumulating', in Men, Books, and Mountains. Essays by Leslie Stephen (London: Hogarth Press, 1956), 131-32. 
for the physical scale of historical reference. Following the $D N B$ 's first appearance as a 63-volume set, publishing innovations have incrementally limited its size: from the first Concise edition (1903) to a 22 -volume second edition (1908), and the DNB on CD-Rom (1996) to the desktop (2004). Now, with responsive platforms, tablets, and smartphones, Stephen's pocket-sized national biography is no longer metaphorical.

National biography as a means of studying a nation's past, broadly conceived, leads to a third and final proposal: that, as digital resources, dictionaries should be better promoted as a source for original historical research-to interpret and study the past in ways impossible without the availability of a collection online. This potential for national biographies as a starting point for research, rather than as 'mere' repositories of existing knowledge first featured in perceptive early reviews of the Oxford $D N B$. Writing in 2005, the literary scholar Alison Booth noted how digital editions offered 'almost boundless possibilities for interweaving lives, the prosopographer's dream', while Stefan Collini predicted 'generations to come making use of this vast consolidation of scholarly accuracy for purposes of their own that may be barely imaginable to us now' ${ }^{31}$ More recently (and once again in this volume), Melanie Nolan has drawn attention to the 'research potential' of the $A D B$ online 'to study the associational patterns of Australians and their place in biographical history', a projection reiterated in Paul Arthur's identification of 'unprecedented ... research opportunities ... for "making and re-making" aspects of the Australian story. ${ }^{32}$ Nor is this a wholly modern perspective; indeed, appreciations of the national biography's utility for humanities and social scientific research have a long history. Published in 1904, Havelock Ellis's Study of British Genius used the DNB to 'obtain a comprehensive view of the men and women who have chiefly built up English civilization', while studies produced over the following two decades considered occupational choices in father/son relations, educational cohorts, and the psychology of celebrity. ${ }^{33}$

31 Booth, 'Fighting for Lives', 269; Stefan Collini, 'National Lives', in his Common Reading: Critics, Historians, Publics (Oxford: Oxford University Press, 2008), 315.

32 Melanie Nolan, 'From Book to Digital Culture: Redesigning the $A D B$ ', in Nolan and Fernon, The ADB's Story, 392. doi.org/10.22459/ADBS.10.2013.12; Arthur, 'Re-imagining a Nation', 110.

33 Havelock Ellis, A Study of British Genius (London: Hurst and Blackett, 1904), 1. Other early research publications drawing on $D N B$ data include Emily Perrin, 'On the Contingency Between Occupation in the Case of Fathers and Sons', Biometrika 3, no. 4 (1904): 467-69. doi.org/10.2307/ 2331733; and Joseph Schneider, 'The Cultural Situation as a Condition for the Achievement of Fame', American Sociological Review 2, no. 4 (1937): 480-91. doi.org/10.2307/2084767. 
The contemporary research aspirations of Booth and Collini and others are welcome and have been taken up to a degree. Publication of the Oxford DNB in 2004 gave rise to a series of scholarly articles, divided broadly between specialist surveys of inclusion and coverage, and studies of historical themes drawing on Dictionary content. ${ }^{34}$ But it remains striking that there are not more instances of scholarly research based on the Oxford $D N B$, and on other national biographies—given the scale of the available corpus and its flexibility in a richly coded online edition, and its potential for 'big data' and 'distant reading' analyses. When it has been undertaken, research to date has tended towards studies that engage online national collections as a tool for finding and grouping. By contrast, getting students and academics to appreciate the potential of online national biography - and particularly its underlying metadata-for new forms of enquiry has proved harder than might have been expected.

There are, of course, a few exceptions, of which 'Six Degrees of Francis Bacon', designed by a collaboration of literary scholars and digital humanists from the universities of Carnegie Mellon and Georgetown, is a leading example. ${ }^{35}$ Their project is an interactive visual reconstruction of the social network of early modern Britain, comprising 13,000 historical individuals and more than 200,000 potential relationships. ${ }^{36}$ At the heart of 'Six Degrees' are those figures active between 1500 and 1700 with entries in the Oxford DNB. Starting with the Dictionary text, and by applying named-entity recognition software, the project created structured data

34 Examples include Helen Foxhall Forbes, Matthias Ammon, Elizabeth Boyle, Conan T. Doyle, Peter D. Evan, Rosa Maria Fera, Paul Gazzoli, Helen Imhoff, Anna Matheson, Sophie Rixon, and Levi Roach, 'Anglo-Saxon and Related Entries in the Oxford Dictionary of National Biography', Anglo-Saxon England 37 (2008): 183-232. doi.org/10.1017/S0263675109990202; Ruth Watts, 'Collecting Women's Lives in "National" History: Opportunities and Challenges in Writing for the ODNB', Women's History Review 19, no. 1 (2010): 109-24. doi.org/10.1080/09612020903444700; Christine MacLeod and Alessandro Nuvolari, 'The Pitfalls of Prosopography: Inventors in the Dictionary of National Biography', Technology and Culture 47, no. 4 (2006): 757-76. doi.org/10.1353/ tech.2006.0240; Helen O'Neill, 'The London Library and the Intelligentsia of Victorian London', Carlyle Studies Annual 31 (2015): 183-215.

35 'Six Degrees of Francis Bacon', accessed 21 April 2017, www.sixdegreesoffrancisbacon.com/.

36 Christopher N. Warren, Daniel Shore, Jessica Otis, Lawrence Wang, Mike Finegold, and Cosma Shalizi, 'Six Degrees of Francis Bacon: A Statistical Method for Reconstructing Large Historical Social Networks', Digital Humanities Quarterly 10, no. 3 (2016), digitalhumanities.org/dhq/ $\mathrm{vol} / 10 / 3 / 000244 / 000244 . h t m l$. On historians' growing interest in social networks, especially within the field of digital humanities, see Joanna Innes, "Networks” in British History', East Asian Journal of British History 5 (2016): 51-72; Ruth Ahnert, 'Maps Versus Networks', in News Networks in Early Modern Europe, eds Noah Moxham and Joad Raymond (Leiden: Brill, 2016), 130-57. doi.org/10.1163/ 9789004277199_006; and Dan Edelstein, Paula Findlen, Giovanna Ceserani, Caroline Winterer, and Nicole Coleman, 'Historical Research in a Digital Age: Reflections From the Mapping the Republic of Letters Project', American Historical Review 122, no. 2 (2017): 400-24. doi.org/10.1093/ahr/122.2.400. 
initially to extract personal names (appearing on five or more occasions) and then to infer social relationships-who knew whom-based on the incidence and relation of personal names within individual $O D N B$ entries. The outcomes are probabilistic and the network visualisation of early modern social relations remains suggestive-based as it is on written (and edited) Dictionary texts rather than proven relations. Nonetheless, the findings are of considerable interest, not least in allowing users to identify those individuals (nodes) who do not themselves have entries in the Oxford $D N B$, but who are rich in social contacts (edges). Analysis of 'high-degree nodes without ODNB entries shows an intriguingly high representation of schoolmasters and publishers'; that is, little-known figures who, being of note in early modern intellectual life, prompt further research and possible inclusion in a national biography. ${ }^{37}$

It seems likely that future journeys of national biography in an age of digital history will take one of several directions. A further outcome from the 'Six Degrees' project has been to identify the estimated 450,000 discrete persons mentioned across the Oxford DNB's 72 million words of text. The great majority of these names will remain just that, never meriting new research let alone a freestanding entry. At the same time, as many as 250,000 historical figures are mentioned on account of their having been close family or professional relations of full Dictionary subjects, and for whom the Dictionary holds well-structured data comprising names, life dates, occupations, and places of association. There is certainly the scope here, aided by private researchers and genealogists, to add to what is known about this 'secondary family' category of lives, with the outcomes of this research perhaps sitting alongside, and linked to, the main Dictionary. In doing so, we might move closer to Keith Thomas's notion of a richer, more extensive national biography, without compromising the $O D N B$ as a record of historically informed noteworthiness.

37 Warrenetal., 'Six Degrees of Francis Bacon', digitalhumanities.org/dhq/vol/10/3/000244/000244. html\#p44. For further research findings from this project, see series of posts by Jessica M. Otis on 'Tales from the Raw NER Data', 'Six Degrees of Francis Bacon: Reassembling the Early Modern Social Network', accessed 23 April 2017, 6dfb.tumblr.com/tagged/tales-from-the-raw-ner-data/. 
There are opportunities too for digital humanists working with current and future generations of national biographers. In collaboration with the Oxford DNB, Christopher Warren, co-creator of 'Six Degrees of Francis Bacon', is currently engaged in a 'distant reading' of the complete Dictionary corpus for what it can tell us both about historical identities and networks of association, place, and kinship, and the historiographical preoccupations of its authors and editors. ${ }^{38}$ Those editors-conscious of the complexities and mutability of personal identities, and their many variations in multiple datasets - are also mindful of the research potential of standardised and linked data. Working again with Wikipedians, the $O D N B$ has mapped the unique identifiers for the majority of its 60,000 main subjects to Wikipedia metadata (Wikidata). As the providers of equivalent data do likewise, the potential to link between biographical content in discrete resources and to related content (including personal relations, creative works, or places visited) — and at a scale that exceeds those handcrafted linking projects described earlier-becomes ever greater. ${ }^{39}$

Given these opportunities, it is striking that more has not been done to better integrate existing national biographies. At the first Canberra conference one of the most confident predictions, born of forthcoming 'electronic' editions, was the seemingly inevitable shift to European, imperial, or world collections of biography. On that occasion it was Matthew's assertion that 'in the course of the next fifty years we will see the gradual aggregation of our various dictionaries of national biography. We will be much blamed by our users if we do not!'40 More than 20 years into this timetable, Matthew's words seem as, if not more, relevant given twenty-first-century interest in transnational history and its discontents. That relatively little has been achieved here owes much to the pull of the national in national biography, as well as to limited resources for expansion and the challenges of sharing content between several publishers and funding models. And yet, through closer integration of national dictionaries we hold open the possibility of forms of transnational history

38 Franco Moretti, Distant Reading (London: Verso, 2013); Christopher N. Warren, 'Historiography's Two Voices: Data Infrastructure and History at Scale in the Oxford Dictionary of National Biography (ODNB)', Journal of Cultural Analytics (November 2018). doi.org/10.31235/osf. io/rbkdh.

39 Andrew Gray, 'Introducing: Six Degrees on Wikidata', in 'Six Degrees of Francis Bacon: Reassembling the Early Modern Social Network', accessed 26 June 2017, 6dfb.tumblr.com/post/ 161020960651/introducing-six-degrees-on-wikidata.

40 Matthew, 'Dictionaries of National Biography', 17. 
shaped, informed, and humanised by historical biography. Global history, which at first sight appears to threaten the purpose of national biography, may prove a discipline to which the genre has much to contribute. ${ }^{41}$

This chapter began by questioning whether contemporary national biographers should speak of their work with the same confidence as earlier generations of dictionary makers, including those who attended the first Canberra conference nearly a quarter of a century ago. To an extent, this caution is justified. Transformations in digital research and publishing present competitors and challenges unforeseeable by those who gathered to propose the future of national biography in the mid-1990s. And yet, while the nature of and potential for national biography is changing fast, the genre- ever prone to debate regarding its purpose—is far from undergoing an existential crisis.

Rather, contemporary national biography serves multiple purposes: from traditional qualities - such as quick reference, background reading, and fact-checking - to newer opportunities for tracing a single life through linked online resources, and the potential for big data research into professions, networks, and places over time. Consequently, modern national biographers are thinking more carefully about the relationship between national biography and history, and the opportunities for national biography to ensure more personal and humane perspectives on 'big' digital and global histories, and to assert the genre's relevance and research potential.

The availability of online national biography and new digital historical approaches may indeed provide new opportunities for intersecting biography and history, though greater efforts are undoubtedly required from national biographers working in collaboration and with researchers. But here, again, we should be mindful how the journeys of national biography-and of the British Dictionary of National Biography in

41 On the relationship of biography and global history, see, for example, Margot Finn, 'AngloIndian Lives in the Later Eighteenth and Early Nineteenth Centuries', Journal for Eighteenth-Century Studies 33, no. 1 (2010): 49-65. doi.org/10.1111/j.1754-0208.2009.00210.x; Miles Ogborn, Global Lives: Britain and the World, 1500-1800 (Cambridge: Cambridge University Press, 2008); Jeffrey A. Fortin and Mark Meuwerel, eds, Atlantic Biographies: Individuals and People in the Atlantic World (Leiden: Brill, 2014); and Francesca Trivellato, 'Is There a Future for Italian Microhistory in the Age of Global History?', California Italian Studies 2, no. 1 (2011), accessed 26 June 2017, escholarship. org/uc/item/0z94n9hq. Book-length studies that elide the biographical, global, and microhistorical include Linda Colley, The Ordeal of Elizabeth Marsh (London: Harper Press, 2007) and Natalie Zemon Davis, Trickster Travels: The Search for Leo Africanus (London: Faber and Faber, 2007). 
particular-are evolutionary and organic. As a result, much of what we do now, and will likely do in years to come, remains a variation of a long-standing principle. Addressing his audience in January 1896, Sidney Lee set down a mark, similar to this chapter, with his challenge to the 'English historian' to embrace 'pedestrian biography' as a source, 'for he will shortly have at his command a completed register of national biography'. ${ }^{42}$ Later that year, Leslie Stephen also considered 'what national biography was for', and provided a response of characteristic insight. As he wrote on that occasion: 'the proper office of the national biographer is to facilitate what I may call the proper reaction between biography and history; to make each throw all possible light on the other'. ${ }^{43}$ Though in markedly different, and now rapidly evolving, contexts, it is an end on which national biographers-past, present, and future-share common purpose. 
This text is taken from 'True Biographies of Nations?': The Cultural Journeys of Dictionaries of National Biography, edited by Karen Fox, published 2019 by ANU Press, The Australian National University, Canberra, Australia.

doi.org/10.22459/TBN.2019.04 